\title{
Caracterização e aproveitamento dos resíduos de argila e argilito provenientes da extração de gipsita no município de Araripina-Brasil como matérias-primas para cerâmica vermelha
}

\author{
(Characterization and utilization of the wastes of clay and argillite \\ from the extraction of gypsum in the municipality of Araripina-Brazil \\ as raw materials for red ceramics)
}

\author{
P. B. Cipriano ${ }^{1 *}, A$. V. Ferraz ${ }^{1}$ \\ ${ }^{I}$ Universidade Federal do Vale do São Francisco, Instituto de Pesquisa em Ciência dos Materiais, Av. Antônio \\ Carlos Magalhães 510, 48902-300, Juazeiro, Bahia, Brasil
}

\begin{abstract}
Resumo
O objetivo deste trabalho foi a caracterização e o aproveitamento dos resíduos de duas argilas (B e C, coletadas em diferentes camadas do capeamento) e argilito, gerados da extração da gipsita no município de Araripina, para a aplicação em cerâmica vermelha. Foram preparados os corpos de prova cerâmicos utilizando as argilas residuais com a incorporação de $40 \%$, $50 \%$ e $80 \%$ de argilito, moldados por compressão, secos a $110^{\circ} \mathrm{C}$ e sinterizados a 850,950 e $1050{ }^{\circ} \mathrm{C}$ durante $2 \mathrm{~h}$. Em seguida, foram avaliadas a absorção de água, retração linear, perda ao fogo, porosidade aparente, massa específica aparente, resistência à flexão em três pontos e microestrutura da superfície de fratura. O uso das argilas residuais com o teor máximo de $50 \%$ de argilito mostrou-se viável em cerâmica vermelha. Os melhores resultados foram obtidos nos corpos cerâmicos com a argila B (contendo montmorilonita) com adição de $40 \%$ e $50 \%$ de argilito em relação à argila $\mathrm{C}$.

Palavras-chave: argila, Araripina, argilito, gipsita, cerâmica vermelha.
\end{abstract}

Abstract

The objective of this study was to characterize and explore wastes of two clays ( $B$ and $C$, collected at different soil layers) and argillite, generated during the extraction of gypsum in the municipality of Araripina-Brazil, for application in red ceramics. Ceramic samples were prepared using residual clays with additions of $40 \%, 50 \%$ and $80 \%$ of argillite, compression-molded, dried at $110{ }^{\circ} \mathrm{C}$ and sintered at 850, 950 and $1050^{\circ} \mathrm{C}$ for $2 \mathrm{~h}$. Then, water absorption, linear retraction, loss on ignition, apparent porosity, apparent specific gravity, three-point flexural strength and microstructure of fracture surface were evaluated. The use of residual clays with a maximum content of 50\% of argillite showed feasible in red ceramics. The best results were obtained in the ceramic bodies with clay $B$ (containing montmorillonite) with addition of $40 \%$ and $50 \%$ of argillite in relation to clay $C$.

Keywords: clay, Araripina, argillite, gypsum, red ceramics.

\section{INTRODUÇÃO}

A Chapada do Araripe no semiárido pernambucano corresponde a uma sequência sedimentar cretácea, rica no minério gipsita, que após o processo de calcinação produz o gesso, gerando o desenvolvimento econômico da região [1]. No entanto, para a extração da gipsita é necessário aprofundar a mina com a movimentação de grandes volumes de solo e resíduos da sobrecarga [2]. Logo, pilhas grandes de resíduos são geradas nas mineradoras, representando uma das principais fontes de impacto ambiental da atividade; essas são compostas por materiais finos devido ao desmonte da rocha e pelo material estéril retirado na operação de

*pamela.ufcg@gmail.com

Dhttps://orcid.org/0000-0002-3013-3854 lavra [3]. Na mineração da gipsita, geralmente ocorre na lavra a limpeza do terreno, o decapeamento, a perfuração, o desmonte, a fragmentação, o carregamento e o transporte [4]. De acordo com o Balanço Mineral Brasileiro (2011), as minas de Pernambuco apresentam um método de lavra semelhante e utilizam como limite operacional uma relação estéril/minério em torno de $0,43 \mathrm{~m}^{3}$ de capeamento para cada tonelada de gipsita extraída. O gesso vem sendo muito utilizado na região em fábricas de placas e blocos, sem levar em consideração os inúmeros danos causados ao meio ambiente e à saúde da população, tendo alto volume de resíduos gerado em sua cadeia produtiva que geralmente não tem um descarte adequado [5]. O estudo da viabilidade para realizar o aproveitamento de materiais residuais gerados pela mineração é de grande importância, pois visa minimizar os impactos ambientais dessa atividade. 
O capeamento na região de Araripina-PE, pertencente à Chapada do Araripe, é formado principalmente por camadas de material argiloso e argilito. $\mathrm{O}$ argilito é uma rocha sedimentar e seu comportamento mecânico apresenta algumas características semelhantes aos solos e às rochas, isto é, na presença de quartzo e carbonato é rígido [6]. A composição química e mineralógica do argilito é semelhante à das argilas [7]. $\mathrm{O}$ argilito é considerado uma matéria-prima de menor valor agregado, possibilitando uma diminuição no custo em aplicações técnicas. Estudos realizados mostraram que a incorporação de $30 \%$ de argilito em uma argila plástica caulinítica de Campos dos Goytacazes melhorou de forma significativa a trabalhabilidade, reduzindo a porosidade e a absorção de água, além de aumentar a resistência mecânica, quando comparada com a massa industrial de telhas local [8]. Microestrutura mais compacta e densa apresentando menos poros foi obtida em uma massa de cerâmica argilosa contendo $50 \%$ de argilito sinterizada a 950 e $1050{ }^{\circ} \mathrm{C}$. O argilito proporcionou um aumento da hematita nas fases de queima [9]. Na literatura, estudos foram realizados utilizando as argilas que recobrem as jazidas de gipsita do Polo Gesseiro na região de Araripina-PE para a produção de produtos de cerâmica vermelha. Os autores mostraram que as argilas apresentaram características para extrusão de tijolos [10]. Foram produzidos compósitos prensados de cerâmica com resíduo de gesso sinterizados a 800 e $1050{ }^{\circ} \mathrm{C}$, permitindo a redução dos impactos ambientais e a possibilidade de novas formulações para produtos de cerâmica vermelha [11].

Considerando a importância da redução de acúmulos de resíduos produzidos na atividade da mineração da gipsita e o bom desempenho da adição de argilito em produtos de cerâmica vermelha, procurou-se neste trabalho caracterizar as camadas de argila e argilito e incorporar $40 \%, 50 \%$ e $80 \%$ de argilito em duas argilas utilizadas industrialmente, avaliando-se a influência do teor de argilito nas propriedades tecnológicas dos produtos. Desta forma, busca-se agregar valor às peças cerâmicas, reduzir o impacto ambiental com a aplicação dos resíduos e melhorar a competitividade do Polo Gesseiro do Araripe no mercado.

\section{MATERIAIS E MÉTODOS}

Os materiais estudados, argilito (A) e duas argilas (B e C) gerados como resíduos durante a etapa de remoção do capeamento de solo sobre a gipsita na extração do minério, foram fornecidos pela Ecogesso Ind. Com. provenientes da reserva situada na área rural do sítio Caruá, localizado no município de Araripina em Pernambuco. A identificação das argilas B e C utilizadas na indústria indicou que foram coletadas manualmente em diferentes camadas do capeamento. A homogeneização e desagregação das amostras foram realizadas após a secagem em estufa a $60{ }^{\circ} \mathrm{C}$ durante $24 \mathrm{~h}$. Nas amostras B e C, realizou-se o procedimento manualmente com o auxílio de um almofariz, enquanto que a amostra $\mathrm{A}$ foi submetida à moagem durante 60 min por via seca em moinho de bolas (Pavitest, I-3021) operado a aproximadamente $30 \mathrm{rpm}$.

A análise granulométrica foi realizada por peneiramento e sedimentação, através do procedimento da norma NBR 7181 [12]. Os limites de liquidez e de plasticidade foram obtidos através das normas NBR 6459 [13] e 7180 [14], respectivamente. A composição química foi determinada por fluorescência de raios X, num equipamento da Shimadzu (EDX 720). A caracterização mineralógica foi realizada através da difração de raios $\mathrm{X}$, com o equipamento Bruker (D8 Advance) utilizando radiação $K \alpha$ do cobre $(\lambda=0,15418 \mathrm{~nm})$, operado a 30 $\mathrm{kV}$ e $40 \mathrm{~mA}$ na temperatura ambiente. Os difratogramas foram obtidos com $2 \theta$ variando de 0 a $120^{\circ}$ e uma velocidade de varredura de $2^{\circ} \cdot \mathrm{min}^{-1}$ e passo de $0,02^{\circ}$. A análise dos picos foi realizada utilizando o software $X^{\prime}$ Pert HighScore Plus v. 2.0a comparando com os padrões dos arquivos cristalográficos do PDF2. As amostras foram submetidas à análise térmica diferencial e termogravimétrica (ATD/TG), através de um equipamento de análise simultânea da Shimadzu (TGA-50). A análise foi realizada em cadinho de platina com massa de aproximadamente $10 \mathrm{mg}$, sob atmosfera de nitrogênio com fluxo do gás de $50 \mathrm{~mL} \cdot \mathrm{min}^{-1}$. As amostras foram aquecidas de 24 até $1000^{\circ} \mathrm{C}$, com taxa de aquecimento $10^{\circ} \mathrm{C} \cdot \mathrm{min}^{-1}$.

Após a caracterização dos resíduos, foram preparadas as amostras cerâmicas, incorporando nas argilas (B e C) os teores de $40 \%, 50 \%$ e $80 \%$ de argilito (A). A massa cerâmica foi homogeneizada com $8 \%$ de água. Os corpos de prova foram conformados por prensagem utilizando um molde retangular de $60 \times 20 \times 5 \mathrm{~mm}^{3}$, aplicando uma pressão uniaxial de $20 \mathrm{MPa}$. Em seguida foram secos a $110^{\circ} \mathrm{C}$ por $24 \mathrm{~h}$ e submetidos à queima a 850,950 e $1050{ }^{\circ} \mathrm{C}$ com taxa de aquecimento de $2{ }^{\circ} \mathrm{C} \cdot \mathrm{min}^{-1}$ durante $2 \mathrm{~h}$. Foram avaliadas a absorção de água (AA), retração linear de queima (RLQ), perda ao fogo $(\mathrm{PF})$, massa específica aparente (MEA), porosidade aparente (PA) e resistência à flexão em três pontos (TRF) com velocidade de aplicação da carga de $0,5 \mathrm{~mm} . \mathrm{min}^{-1}$. Os resultados foram reportados à média de 5 corpos de prova para cada composição. A morfologia da superfície de fratura dos corpos de prova cerâmicos queimados, após o ensaio de resistência a flexão, foi analisada em um microscópio eletrônico de varredura (MEV) da Tescan (Vega 3XMU) com magnificação de 4000x. As amostras foram recobertas com ouro durante $10 \mathrm{~min}$ e corrente de $15 \mathrm{~mA}$, utilizando um equipamento da Quorum (Q150R ES).

\section{RESULTADOS E DISCUSSÃO}

A análise química quantitativa determinou os teores de óxidos presentes nas amostras (Tabela I). A composição química permite, em conjunto com as propriedades físicas, uma avaliação tecnológica para aplicação dos resíduos. Em depósitos de argila, a composição da mistura dos argilominerais pode variar em uma pequena extensão [15], entretanto os resíduos apresentaram uma composição semelhante mesmo sendo obtidos de camadas diferentes. Observou-se que os óxidos majoritários foram o óxido de silício e a alumina em todas as amostras. A presença de óxidos fundentes $\left(\mathrm{CaO}, \mathrm{MgO}, \mathrm{K}_{2} \mathrm{O}\right.$ e $\left.\mathrm{Fe}_{2} \mathrm{O}_{3}\right)$ é importante 
durante a etapa de queima no processamento de materiais de cerâmica vermelha, pois quanto maior a sua quantidade menor é a temperatura de queima [16]. Os demais óxidos apresentaram-se como traços de impurezas no material em teores inferiores a $4 \%$ em todas as amostras analisadas. $\mathrm{O}$ argilito estudado apresentou uma composição química semelhante ao encontrado no argilito em Santa Gertrudes, São Paulo [17]. As amostras apresentaram teores maiores que $50 \%$ de sílica e $20 \%$ de alumina, que podem ser atribuídos às camadas tetraédricas e octaédricas da estrutura dos argilominerais, dos grupos das esmectitas e caulinitas, e dos minerais acessórios [18]. $\mathrm{O}$ teor de $\mathrm{Fe}_{2} \mathrm{O}_{3}$ variou entre $6 \%$ e $8 \%$ nas amostras analisadas e pode ser decorrente da camada octaédrica da esmectita ou de minerais acessórios na forma de hematita; esse óxido proporciona uma coloração avermelhada às massas cerâmicas após a queima [19]. O $\mathrm{K}_{2} \mathrm{O}$ foi proveniente da ilita, mica e feldspato [20], enquanto que o $\mathrm{MgO}$ apresentou teores inferiores a $2 \%$ que pode ser atribuído à camada octaédrica da esmectita ou ao carbonato de magnésio. $\mathrm{O} \mathrm{CaO}$ possivelmente foi devido à presença do mineral acessório calcita; a amostra $\mathrm{B}$ apresentou o maior teor desse óxido dentre as amostras. As amostras apresentaram perda ao fogo entre $10 \%$ e $13 \%$, o que foi relacionada à perda de águas coordenadas e adsorvidas, hidroxilas dos argilominerais, carbonatos, matéria orgânica e outros [21].

A distribuição granulométrica dos resíduos de Araripina foi obtida nas faixas de tamanhos das partículas referente à

Tabela I - Resultados (\% em massa) da análise química quantitativa por fluorescência de raios X.

[Table I - Results (wt\%) of quantitative chemical analysis by $X$-ray fluorescence.]

\begin{tabular}{cccc}
\hline $\mathrm{Amostra}$ & $\mathrm{A}$ & $\mathrm{B}$ & $\mathrm{C}$ \\
\hline $\mathrm{SiO}_{2}$ & 58,73 & 60,35 & 65,43 \\
$\mathrm{Al}_{2} \mathrm{O}_{3}$ & 25,51 & 22,65 & 21,94 \\
$\mathrm{Fe}_{2} \mathrm{O}_{3}$ & 6,60 & 8,01 & 6,18 \\
$\mathrm{~K}_{2} \mathrm{O}$ & 3,59 & 2,05 & 2,23 \\
$\mathrm{MgO}$ & 1,78 & 1,45 & 0,93 \\
$\mathrm{SO}_{3}$ & 1,60 & 0,46 & 0,18 \\
$\mathrm{CaO}$ & 0,64 & 3,23 & 0,90 \\
$\mathrm{P}_{2} \mathrm{O}_{5}$ & 0,59 & 0,57 & 0,86 \\
$\mathrm{TiO}_{2}$ & 0,46 & 0,72 & 0,82 \\
$\mathrm{BaO}_{\mathrm{CuO}}$ & 0,35 & 0,30 & 0,34 \\
$\mathrm{MnO}$ & 0,04 & 0,03 & - \\
$\mathrm{Cr}_{2} \mathrm{O}_{3}$ & 0,04 & 0,15 & 0,17 \\
$\mathrm{ZnO}$ & 0,03 & - & - \\
$\mathrm{Rb}_{2} \mathrm{O}$ & 0,02 & 0,01 & 0,01 \\
$\mathrm{SrO}$ & 0,10 & 0,02 & 0,01 \\
$\mathrm{PF} *$ & 12,86 & 10,82 & 0,01 \\
\hline
\end{tabular}

* - perda ao fogo. proporção de argila $(\mathrm{D}<2 \mu \mathrm{m})$, silte $(2<\mathrm{D}<20 \mu \mathrm{m})$ e areia (D $>20 \mu \mathrm{m}$, Fig. 1). As amostras apresentaram tamanho de partícula predominante associado à fração areia. Após a moagem a amostra A apresentou um teor mais elevado da fração argila e silte, quando comparada com as amostras B e C, que tiveram comportamento semelhante. Esse comportamento para a amostra $\mathrm{A}$ foi devido à sua característica de granulação finíssima, visto que o argilito é uma rocha sedimentar constituída essencialmente por partículas argilosas [22]. O elevado teor de silte pode estar relacionado às características da origem e evolução da formação local dos sedimentos [23]. As frações de silte e areia são formadas basicamente por quartzo; esse mineral foi observado no difratograma de raios $\mathrm{X}$. As diferentes frações granulométricas que compuseram os resíduos foram importantes no balanceamento das propriedades, pois a granulometria de uma argila tem correlação com a composição mineralógica e apresenta importância nas etapas de processamento como conformação, secagem e sinterização [24].

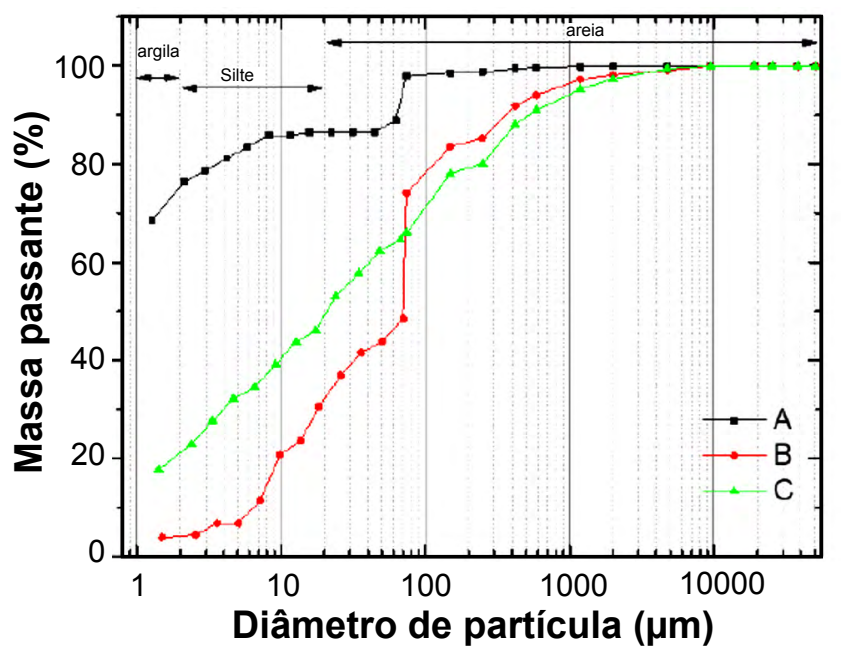

Figura 1: Curvas de distribuição granulométrica dos resíduos. [Figure 1: Particle size distribution curves of the wastes.]

A plasticidade das massas industriais é resultado de uma relação físico-química entre as partículas coloidais de argila e a água, que depende também da composição química e mineralógica, da morfologia das partículas e do teor da fração argila que interferem no preparo e nas propriedades finais dos produtos cerâmicos $[25,26]$. Os resultados dos ensaios de limite de plasticidade, limite de liquidez e índice de plasticidade das amostras são apresentados na Tabela II. O limite de plasticidade está relacionado com a quantidade de água adicionada na argila para a etapa de moldagem, importante para o processamento em aplicações tecnológicas [18]. Os limites de plasticidade entre $18 \%$ e $30 \%$ e o índice de plasticidade variando entre $10 \%$ e $35 \%$ foram encontrados nas amostras A e B; esses valores são aceitáveis para o processamento industrial de tijolos e telhas [27]. Todos os índices de plasticidades determinados foram maiores que $15 \%$, classificando os resíduos como materiais 
altamente plásticos [28]. O maior limite de plasticidade da amostra $\mathrm{B}$ em relação à amostra $\mathrm{C}$ pode estar relacionado à presença do argilomineral montmorilonita (Fig. 2), que apresenta elevada finura e contém matéria orgânica na forma de coloides protetores. Portanto, são importantes em argilas utilizadas na cerâmica estrutural, pois contribui com a plasticidade e com o comportamento durante a queima [29]. Não foi possível determinar o limite de liquidez da amostra $\mathrm{A}$, pois à medida que se adicionou água para adequar a consistência do material às condições de ensaio a amostra aglomerou. Provavelmente esse comportamento foi associado à menor esfoliação da amostra, assim havendo uma menor desagregação das partículas. Para os argilitos é esperada uma maior esfoliação quando umedecidos à medida que a fração argila aumenta, pois existe uma correlação entre essa fração e o seu comportamento. Uma quantidade da fração argila variando aproximadamente entre $64 \%$ e $67 \%$ é capaz de reduzir o grau de esfoliação; este teor foi semelhante ao encontrado na Fig. 1 [23]. O argilito quando umedecido apresentou untuosidade ao tato característico desse material.

Tabela II - Índices de Atterberg.

[Table II - Atterberg indices.]

\begin{tabular}{lccc}
\hline \multicolumn{1}{c}{ Amostra } & A & B & C \\
\hline Limite de liquidez (\%) & $*$ & 53,44 & 38,86 \\
Limite de plasticidade (\%) & $29,2 \pm 1,3$ & $25,1 \pm 0,4$ & $16,5 \pm 3,0$ \\
Índice de plasticidade (\%) & 29,2 & 28,4 & 22,3 \\
\hline * - não foi possível determinar. & & &
\end{tabular}

A Fig. 2 apresenta os difratogramas de raios $\mathrm{X}$ das amostras in natura. As argilas podem ser compostas por um ou mais argilominerais [30]. A análise mineralógica mostrou que os resíduos de Araripina foram compostos basicamente por argilominerais, como caulinita, montmorilonita e ilita, e outros minerais acessórios geralmente encontrados nas argilas, como quartzo e mica. A amostra A apresentou montmorilonita, caulinita, quartzo, mica e ilita, enquanto que nas amostras B e C observaram-se fases semelhantes de caulinita, mica e quartzo com a presença de montmorilonita apenas em B. Os minerais micáceos apresentam composições variáveis e são encontrados em muitas argilas e argilitos [16]. Estudos mostraram que em argilito no sudeste de Santa Catarina são encontrados os argilominerais esmectita e ilita e que suas características variam de acordo com o nível da mina em que foi coletado [31], bem como os teores de argila, quartzo e calcita nos argilitos variam de acordo com a profundidade [32].

O comportamento térmico das amostras dos resíduos foi analisado pelas curvas TG/ATD (Fig. 3). Observou-se na curva ATD que todas as amostras apresentaram pico endotérmico entre 60 e $130{ }^{\circ} \mathrm{C}$ relacionado à perda de água livre [33]. Na amostra $\mathrm{A}$ foi observado um grande pico endotérmico em aproximadamente $61{ }^{\circ} \mathrm{C}$, com perda de massa em cerca de $6 \%$. O pequeno pico endotérmico a $252{ }^{\circ} \mathrm{C}$ correspondeu à saída de água coordenada

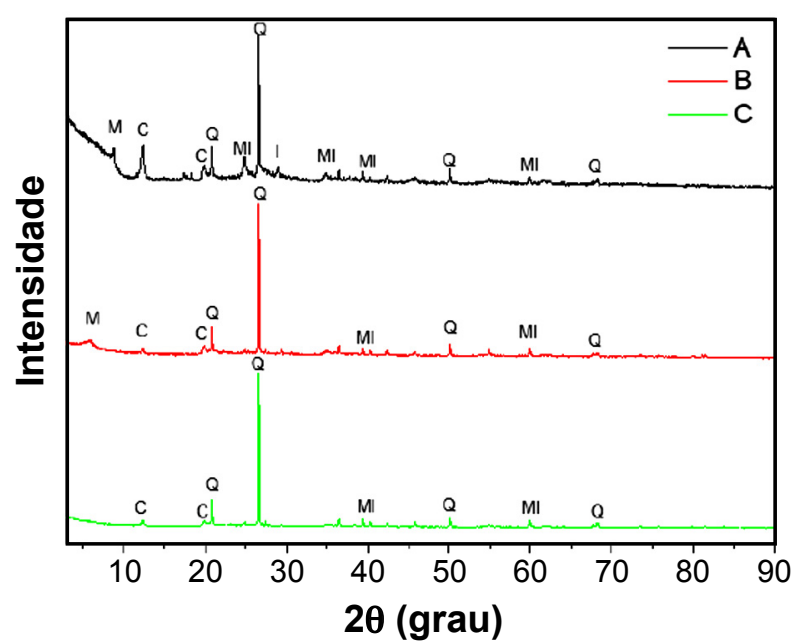

Figura 2: Difratogramas de raios $\mathrm{X}$ dos resíduos. M: montmorilonita (ICSD 00-013-0135), C: caulinita (PDF2 00-029-1488), Q: quartzo (ICSD 201354), MI: mica (PDF2 00-007-0042), I: ilita (PDF2 00024-0495).

[Figure 2: X-ray diffraction patterns of the wastes. M: montmorillonite; C: kaolinite; Q: quartz; MI: mica; I: illite.]

aos cátions [34]. O pico exotérmico em $369^{\circ} \mathrm{C}$ foi relacionado à combustão de matéria orgânica. $\mathrm{O}$ pico em $476{ }^{\circ} \mathrm{C}$ é característico da desidroxilação da caulinita; esse comportamento ratificou a presença de caulinita na amostra de acordo com a difração de raios X [35]. Apenas a amostra A apresentou uma banda exotérmica em torno de $800{ }^{\circ} \mathrm{C}$, que pode estar associada à decomposição da metacaulinita [18], e o pico em $914{ }^{\circ} \mathrm{C}$, possivelmente relacionado ao rearranjo estrutural e à nucleação de mulita, pois a amostra apresentou caulinita e esmectita em sua composição [36]. A presença de mulita é importante para proporcionar aumento na resistência mecânica em produtos cerâmicos [37]. Foram avaliadas temperaturas em torno de $914^{\circ} \mathrm{C}(850,950$ e 1050 $\left.{ }^{\circ} \mathrm{C}\right)$. Logo, as melhores temperaturas de sinterização foram acima de $900{ }^{\circ} \mathrm{C}$ devido à análise térmica sugerir a formação da mulita próxima a essa temperatura e esta fase influenciar as propriedades dos corpos de prova após a queima conforme observado abaixo. As amostras B e C apresentaram um comportamento semelhante; a perda de massa entre 90 e $385^{\circ} \mathrm{C}$ pode ser atribuída à evaporação da água dissolvida e água zeolítica em $160{ }^{\circ} \mathrm{C}$ [38]. A curva ATD apresentou para a amostra $\mathrm{B}$ um pico exotérmico mais acentuado que na amostra $\mathrm{C}$ em aproximadamente $350{ }^{\circ} \mathrm{C}$, possivelmente devido à quantidade maior de matéria orgânica e sua correspondente combustão [18]. Em torno de $400{ }^{\circ} \mathrm{C}$ ocorreu uma perda de massa relacionada com a oxidação da matéria orgânica. Entre 525 e $996{ }^{\circ} \mathrm{C}$ houve uma perda de massa de cerca de $4 \%$ devido possivelmente a um fenômeno de desidroxilação das argilas; esse processo de decomposição é atribuído à ruptura das hidroxilas estruturais, seguido da liberação de água, sendo considerado irreversível [38]. Foi gerado um resíduo entre $86 \%$ e $88 \%$ em todas as amostras estudadas.

A Fig. 4 mostra a absorção de água e a resistência mecânica dos corpos de prova preparados com as argilas B 

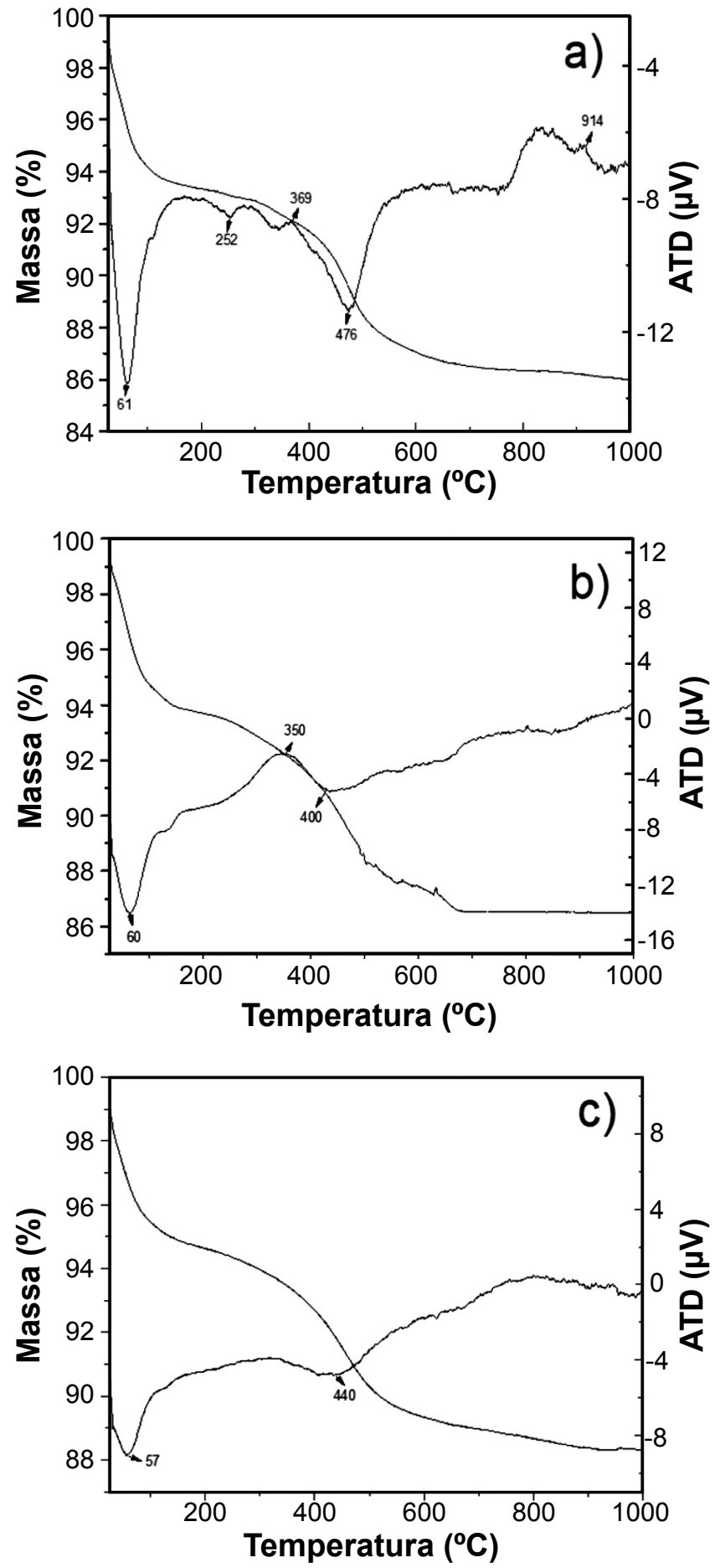

Figura 3: Curvas de TG/ATD das amostras: a) A; b) B; e c) C. [Figure 3: TG/DTA curves of the samples: $a$ ) A; b) B; and c) C.]

e C contendo $40 \%, 50 \%$ e $80 \%$ de A. Os teores de $40 \%$ e $50 \%$ de argilito foram utilizados na literatura em aplicações cerâmicas $[7,8]$ e o teor de $80 \%$ foi testado como limite máximo nesse estudo. Todas as composições apresentaram a coloração avermelhada após a queima, pois os resíduos continham óxido de ferro devido à presença do mineral hematita $\left(\mathrm{Fe}_{2} \mathrm{O}_{3}\right)$, conforme mostrado na análise química por fluorescência de raios $\mathrm{X}$. Uma determinada quantidade de óxido de ferro provavelmente na forma coloidal auxilia a plasticidade e melhora o adensamento, além de possibilitar uma boa sinterização [39]. Quanto maior a temperatura de queima, menor foi à absorção de água em todas as composições estudadas, sendo inferior a 14\%. Esse comportamento pôde ser atribuído à melhor sinterização e redução dos poros obtidos em temperaturas maiores, como observado adiante. A absorção de água dos corpos de prova teve uma redução significativa com a incorporação de $40 \%$ e $50 \%$ de argilito principalmente utilizando a argila B a $950{ }^{\circ} \mathrm{C}$. Na temperatura de queima de $1050{ }^{\circ} \mathrm{C}$, quanto maior o teor de argilito, menor foi a absorção de água; esse comportamento foi semelhante nas argilas B e C. As composições com $80 \%$ de A apresentaram uma redução de aproximadamente $85 \%$ da absorção em relação às argilas. Os resultados obtidos em todas as composições foram adequados para a fabricação de tijolos $(<25 \%)$, telhas $(<20 \%)$ e revestimentos porosos (entre $10 \%$ e $20 \%$ ). As composições com argilito atenderam aos requisitos especificados para a fabricação de revestimentos semiporosos (entre 6\% e 10\%) [40]. Resultados semelhantes foram obtidos para a absorção de água $<20 \%$ nas composições com argilito em uma massa industrial de Campos dos Goytacazes em todas as temperaturas investigadas [8].

As composições contendo argilito apresentaram resistências à flexão superiores à da argila pura, independente do tipo de argila. A presença de argilito aumentou em média $10 \mathrm{MPa}$ a tensão de ruptura à flexão em relação à argila $\mathrm{C}$ e $20 \mathrm{MPa}$ quando comparada à argila $\mathrm{B}$. Quanto maior a temperatura de sinterização, maior foi a resistência à flexão; esse comportamento foi influenciado pela redução da porosidade (Tabela III) [8]. Foram observados resultados semelhantes nos teores de $40 \%$ e $50 \%$ de argilito, enquanto que o teor de $80 \%$ reduziu a propriedade mecânica na argila $\mathrm{B}$ em todas as temperaturas de queima e aumentou apenas na argila $\mathrm{C}$ a $950{ }^{\circ} \mathrm{C}$. As propriedades mecânicas são influenciadas pelas fases formadas, teor de fase vítrea, presença de defeitos e porosidade do material [17]. O óxido de potássio observado na composição química possivelmente proveniente da mica identificada na análise mineralógica (Fig. 2), por ser um óxido fundente, pode ter contribuído na densificação dos corpos de prova. A presença de mulita identificada na análise térmica na amostra A pode ter proporcionado o aumento na resistência mecânica do material cerâmico [37].

A Tabela III mostra a retração linear de queima, perda ao fogo, porosidade aparente e massa específica aparente em função da temperatura de queima dos corpos de prova. A retração linear de queima aumentou de forma proporcional com a temperatura de sinterização. Esse comportamento foi atribuído à vitrificação e densificação que possibilitou a redução da porosidade com aproximação das partículas, devido à tensão superficial da fase líquida [8]. Essas características foram observadas nas micrografias (Figs. 5 e 6), sendo mais efetivas nas amostras preparadas com a argila B. A argila B apresentou uma retração maior em relação à argila C. A retração foi maior nos corpos de prova com a incorporação de argilito comparado com a argila pura. 

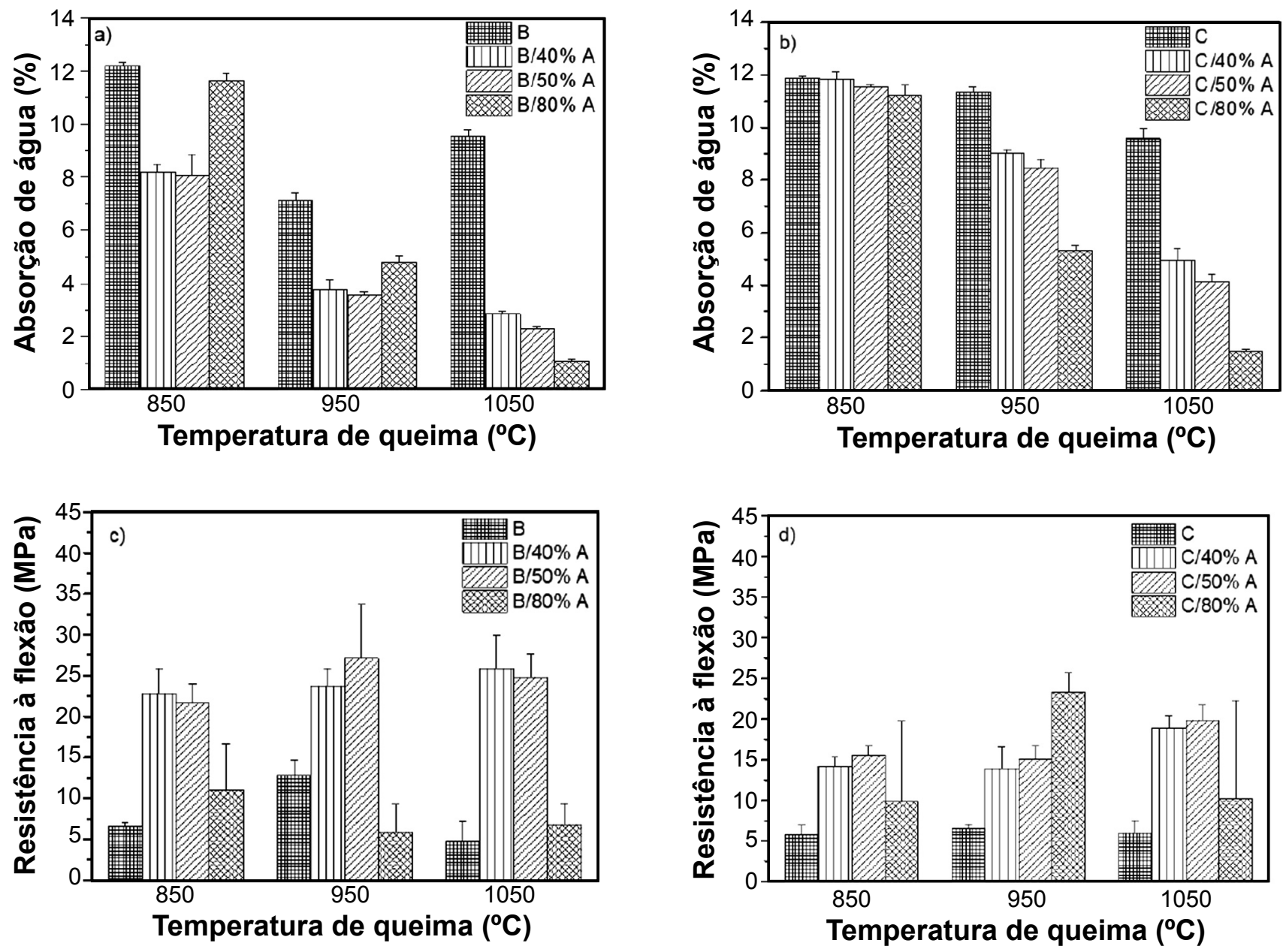

Figura 4: Absorção de água (a,b) e resistência à flexão (c,d) de misturas de argila B e argilito A (a,c) e argila C e argilito A (b,d). [Figure 4: Absorption of water $(a, b)$ and bending strength $(c, d)$ of mixes of clay B and argillite $A(a, c)$ and clay $C$ and argillite $A(b, d)$.]

Quanto maior a porosidade aparente, maior foi a absorção de água nos corpos de prova das composições estudadas. $\mathrm{O}$ argilito proporcionou uma redução significativa na porosidade, devido à vitrificação ocorrida durante a queima e à presença de materiais fundentes e inertes no argilito, que podem contribuir para uma menor porosidade [8]. A tendência da massa específica aparente foi aumentar com o incremento da temperatura de sinterização devido à densificação ocorrida nessa etapa. A adição de argilito nas formulações aumentou a massa específica aparente dos corpos de prova. A perda ao fogo das composições com argilito foi maior do que a argila pura e proporcional à temperatura de queima.

Para avaliação da superfície de fratura dos corpos de prova queimados, foram selecionadas as composições sinterizadas a $950{ }^{\circ} \mathrm{C}$, pois apresentaram as melhores propriedades tecnológicas avaliadas (Fig. 4). A Fig. 5 mostra as micrografias da superfície de fratura das amostras preparadas com as argilas puras $\mathrm{B}$ e $\mathrm{C}$ e seus compósitos com $40 \%, 50 \%$ e $80 \%$ de A. Os corpos cerâmicos formulados com a argila B apresentaram na sinterização regiões mais densificadas. Essas características corroboraram o comportamento mecânico superior das amostras preparadas com a argila $\mathrm{B}$ em relação à argila C (Fig. 4). Em todas as micrografias foram observadas a presença de defeitos na microestrutura que pôde ser atribuído às falhas de empacotamento das partículas [41]. Os corpos de prova com a argila $\mathrm{C}$ apresentaram um aspecto mais rugoso característico de uma sinterização pouco eficiente [42]. A Fig. 6 apresenta as micrografias da superfície de fratura das amostras preparadas com as argilas B e C, contendo $50 \%$ de A, sinterizadas a 850 e $1050{ }^{\circ} \mathrm{C}$. Observou-se que a temperatura de queima de $10500^{\circ} \mathrm{C}$ apresentou uma melhor sinterização em relação a $850{ }^{\circ} \mathrm{C}$ independentemente do tipo de argila. Esse comportamento era esperado, pois quanto maior a temperatura de queima mais eficiente é a sinterização. A argila B apresentou uma maior redução de poros a $1050{ }^{\circ} \mathrm{C}$ quando comparada com a argila C. A textura rugosa em temperaturas de queima inferiores a $1050{ }^{\circ} \mathrm{C}$ foi reportada na literatura como um comportamento esperado, por não ter ocorrido uma consolidação eficiente da microestrutura [43]. A utilização de materiais com baixas frações de argilominerais, principalmente caulinita, ou com elevadas frações de mica, ilita e esmectita vem crescendo devido à redução da disponibilidade de argilas para serem utilizadas como matérias-primas de melhor qualidade 
Tabela III - Propriedades tecnológicas das argilas com 40\%, 50\% e $80 \%$ de argilito.

[Table III - Technological properties of clays with 40\%, 50\% and $80 \%$ of argillite.]

\begin{tabular}{cccccc}
\hline Amostra & TQ $\left({ }^{\circ} \mathrm{C}\right)$ & RLQ $(\%)$ & PF $(\%)$ & PA $(\%)$ & MEA $\left(\mathrm{g} . \mathrm{cm}^{-3}\right)$ \\
\hline \multirow{3}{*}{ B } & 850 & $0,26 \pm 0,13$ & $12,27 \pm 0,11$ & $10,87 \pm 0,11$ & $1,86 \pm 0,30$ \\
& 950 & $2,84 \pm 0,17$ & $14,36 \pm 0,09$ & $15,44 \pm 0,59$ & $2,03 \pm 0,06$ \\
& 1050 & $1,74 \pm 0,18$ & $12,97 \pm 0,06$ & $8,71 \pm 0,21$ & $1,96 \pm 0,04$ \\
\hline \multirow{3}{*}{ /40\% A } & 850 & $2,82 \pm 0,33$ & $14,56 \pm 0,29$ & $15,24 \pm 0,48$ & $1,86 \pm 0,04$ \\
& 950 & $5,54 \pm 0,28$ & $14,89 \pm 0,08$ & $7,85 \pm 0,88$ & $2,10 \pm 0,04$ \\
& 1050 & $6,04 \pm 0,08$ & $14,93 \pm 0,12$ & $5,92 \pm 0,15$ & $2,10 \pm 0,04$ \\
\hline & 850 & $2,95 \pm 0,23$ & $14,61 \pm 0,14$ & $14,74 \pm 1,30$ & $1,84 \pm 0,03$ \\
B/50\% A & 950 & $5,51 \pm 0,18$ & $15,04 \pm 0,09$ & $7,37 \pm 0,32$ & $2,08 \pm 0,05$ \\
& 1050 & $6,68 \pm 0,25$ & $15,18 \pm 0,17$ & $5,02 \pm 0,13$ & $2,20 \pm 0,03$ \\
\hline & 850 & $1,93 \pm 0,06$ & $13,56 \pm 0,16$ & $19,80 \pm 0,54$ & $1,70 \pm 0,05$ \\
B/80\% A & 950 & $5,62 \pm 0,14$ & $14,12 \pm 0,21$ & $9,82 \pm 0,32$ & $2,05 \pm 0,03$ \\
& 1050 & $8,02 \pm 0,10$ & $14,13 \pm 0,20$ & $2,50 \pm 0,19$ & $2,33 \pm 0,04$ \\
\hline & 850 & $0,08 \pm 0,09$ & $9,82 \pm 0,11$ & $10,62 \pm 0,06$ & $1,86 \pm 0,01$ \\
C & 950 & $0,48 \pm 0,23$ & $10,62 \pm 0,07$ & $10,21 \pm 0,14$ & $1,89 \pm 0,03$ \\
& 1050 & $1,53 \pm 0,13$ & $10,65 \pm 0,05$ & $8,75 \pm 0,31$ & $1,96 \pm 0,03$ \\
\hline & 850 & $0,75 \pm 0,18$ & $11,91 \pm 0,22$ & $10,57 \pm 0,25$ & $1,80 \pm 0,04$ \\
C/40\% A & 950 & $2,21 \pm 0,06$ & $12,73 \pm 0,04$ & $8,29 \pm 0,12$ & $1,91 \pm 0,05$ \\
& 1050 & $4,75 \pm 0,14$ & $12,92 \pm 0,05$ & $4,73 \pm 0,37$ & $2,12 \pm 0,03$ \\
\hline & 850 & $1,01 \pm 0,08$ & $12,32 \pm 0,05$ & $10,36 \pm 0,09$ & $1,74 \pm 0,12$ \\
C/50\% A & 950 & $2,60 \pm 0,11$ & $13,17 \pm 0,06$ & $7,82 \pm 0,28$ & $1,90 \pm 0,02$ \\
& 1050 & $5,29 \pm 0,29$ & $13,46 \pm 0,02$ & $8,90 \pm 0,53$ & $2,16 \pm 0,02$ \\
\hline & 850 & $1,56 \pm 0,18$ & $13,47 \pm 0,25$ & $10,09 \pm 0,32$ & $1,71 \pm 0,03$ \\
& 950 & $4,95 \pm 0,06$ & $14,57 \pm 0,17$ & $5,05 \pm 0,17$ & $2,00 \pm 0,02$ \\
& 1050 & $7,81 \pm 0,13$ & $14,96 \pm 0,04$ & $3,09 \pm 0,76$ & $2,31 \pm 0,02$ \\
\hline
\end{tabular}

$T Q$ - temperatura de queima; $R L Q$ - retração linear de queima; $P F$ - perda ao fogo; $P A$ - porosidade aparente; MEA - massa específica aparente.
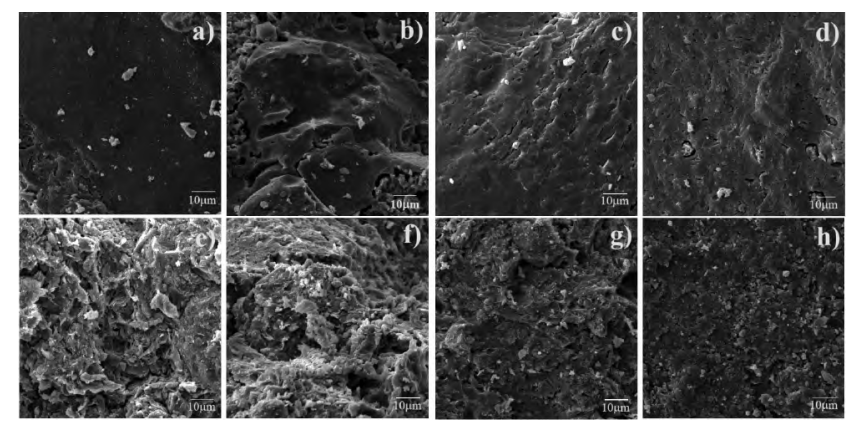

Figura 5: Micrografias de MEV de superfície de fratura dos corpos cerâmicos sinterizados a $950{ }^{\circ} \mathrm{C}$ : a) B; b) B/40\% A; c) B/50\% A; d) $\mathrm{B} / 80 \% \mathrm{~A}$; e) C; f) C/40\% A; g) C/50\% A; e h) C/80\% A.

[Figure 5: SEM micrographs of the fracture surface of sintered ceramic bodies at $950{ }^{\circ} \mathrm{C}$ : a) $\mathrm{B}$; b) $\mathrm{B} / 40 \% \mathrm{~A}$; c) $\mathrm{B} / 50 \% \mathrm{~A}$; d) $\mathrm{B} / 80 \%$ $A$; e) $C$; f) $C / 40 \% A$; g) $C / 50 \% \mathrm{~A}$; and h) $C / 80 \% \mathrm{~A}$.]

para produção de produtos de cerâmica tradicional, logo o aperfeiçoamento das formulações e do processamento é necessário para obter peças com melhor desempenho [44].

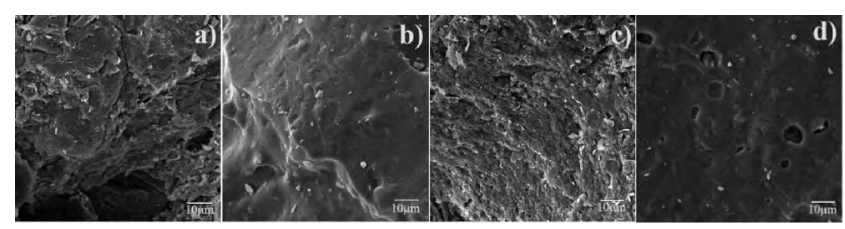

Figura 6: Micrografias de MEV de superfície de fratura das amostras sinterizadas em diferentes temperaturas: a) $\mathrm{B} / 50 \%$ $\mathrm{A}\left(850{ }^{\circ} \mathrm{C}\right)$; b) $\mathrm{B} / 50 \% \mathrm{~A}\left(1050{ }^{\circ} \mathrm{C}\right)$; c) $\mathrm{C} / 50 \% \mathrm{~A}\left(850{ }^{\circ} \mathrm{C}\right)$; e d) $\mathrm{C} / 50 \%$ A $\left(1050{ }^{\circ} \mathrm{C}\right)$.

[Figure 6: SEM micrographs of the fracture surface of samples sintered at different temperatures: a) B/50\% A $\left(850{ }^{\circ} \mathrm{C}\right)$; b) $\mathrm{B} / 50 \%$ $A\left(1050{ }^{\circ} \mathrm{C}\right)$; c) $\mathrm{C} / 50 \% \mathrm{~A}\left(850{ }^{\circ} \mathrm{C}\right)$; and d) $\left.\mathrm{C} / 50 \% \mathrm{~A}\left(1050{ }^{\circ} \mathrm{C}\right).\right]$

\section{CONCLUSÕES}

As argilas residuais (B e C) e o argilito (A) mostraram propriedades adequadas para aplicação em cerâmica vermelha. $\mathrm{O}$ aproveitamento desses resíduos pode contribuir para redução dos impactos ambientais gerados na 
extração da gipsita. Os resíduos analisados apresentaram composições químicas semelhantes. A análise mineralógica mostrou que a amostra A foi formada principalmente pelos argilominerais caulinita, montmorilonita e ilita e outros minerais acessórios como quartzo e mica. As amostras B e $\mathrm{C}$ apresentaram fases semelhantes de caulinita, mica e quartzo com a presença de montmorilonita apenas em B. Os corpos cerâmicos preparados com a argila B apresentaram melhor comportamento mecânico e densificação da microestrutura. A incorporação de argilito proporcionou de forma geral a redução na absorção de água e na porosidade aparente, além de aumentar a resistência mecânica da cerâmica.

\section{AGRADECIMENTOS}

À CAPES, pela concessão da bolsa de pós-doutorado PNPD. À Ecogesso pela doação dos resíduos de argila e de argilito.

\section{REFERÊNCIAS}

[1] C.V.A. Granja, E.P. Cavalcante, H.P.C. Filho, M.S. Siqueira, W. Nascimento, Id Line Multidisc. Psycol. J. 11, 36 (2017) 239.

[2] J.C. Souza, H.C. Rodrigues, S.S. Rocha, F.F. Bastos, Tecnol. Metal. Mater. Miner. 15 (2018) 175.

[3] K.K.S. Melo, A.P.C Lima, M.C. Santana, V.C.P. Andrade, A.L.C. Braga, K.V. Correia, Holos 6 (2017) 214.

[4] J.C. de Souza, R.A. da Silva, F. de F. Bastos, Est. Geol. 23 (2013) 143.

[5] A.J. Santos, C.R.A. Araújo, F.L. Silva, L.A.C.Alexandre, Id Line Multidisc. Psycol. J. 11, 37 (2017) 143.

[6] N. Conil, I. Djeran-Maigre, R. Cabrillac, K. Su, C. R. Mec. 332 (2004) 841.

[7] V.S. Candido, R.M. Pinheiro, S.N. Monteiro, C.M.F. Vieira, Cerâmica 59, 350 (2013) 310.

[8] C.M.F. Vieira, J.V. Emiliano, Cerâmica 59, 351 (2013) 389.

[9] C.M.F. Vieira, R.M. Pinheiro, Cerâmica 59, 352 (2013) 495.

[10] B.B. Lira, S.A.B.C. Rêgo, I.F. Anjos, in $55^{\circ}$ Congr. Bras. Cerâm., Porto Galinhas (2011).

[11] P.B. Cipriano, R.T.O. Rezende, A.V. Ferraz, Acta Bras. 3, 1 (2019) 25.

[12] ABNT NBR 7181, "Solo: análise granulométrica", Ass. Bras. Norm. Técn., Rio Janeiro (1984).

[13] ABNT NBR 6459, "Solo: determinação do limite de liquidez”, Ass. Bras. Norm. Técn., Rio Janeiro (1984).

[14] ABNT NBR 7180, "Solo: determinação do limite de plasticidade", Ass. Bras. Norm. Técn., Rio Janeiro (1984).

[15] É. Teixeira-Neto, Â.A. Teixeira-Neto, Quím. Nova 32, 3 (2009) 809.

[16] F.H. Norton, Introdução à tecnologia cerâmica, Edgard Blucher, S. Paulo (1973).

[17] F.S. Hoffmann, G. Dos Santos, M.R. Morelli, Cerâmica 58, 346 (2012) 174.
[18] P.S. Santos, Ciência e tecnologia de argilas, EDUSP, S. Paulo (1992).

[19] C.M.F. Vieira, J.N.F. de Holanda, D.G. Pinatti, Cerâmica 46, 297 (2000) 14.

[20] P.M. Andrade, H.S.N. Neto, S.N. Monteiro, C.M.F. Vieira, Cerâmica 51, 320 (2005) 361.

[21] R.R. Menezes, P.M. Souto, L.N.L. Santana, G.A. Neves, R.H.G.A. Kiminami, H.C. Ferreira, Cerâmica 55, 334 (2009) 163.

[22] ABNT NBR 6502, "Rochas e solos", Ass. Bras. Norm. Técn., Rio Janeiro (1995).

[23] O.S. Baraúna, "Estudo das argilas que recobrem as camadas de gipsita da bacia sedimentar do Araripe", Dis. Mestr., Un. Fed. Pernambuco, Recife (1991).

[24] C.M.F. Vieira, L.A. Terrones, R. Sánchez, S.N. Monteiro, Cerâmica 53, 327 (2007) 249.

[25] D.M. de Morais, R.M. Sposto, Cerâm. Ind. 11 (2006) 35.

[26] J.R. Goes, T.F. Azevedo, T.X.C. Dutra, V.B. Santos, J.B. Severo Junior, L.S. Barreto, Cerâmica 60, 354 (2014) 211.

[27] M. Dondi, Cerâm. Ind. 11, 3 (2006) 36.

[28] L.F.A. Campos, R.S. de Macedo, P.K. Kiyohara, H.C. Ferreira, Cerâmica 45, 295 (1999) 140.

[29] S.O. Ramos, R.S. Macedo, J.M. Cartaxo, R.R. Menezes, L.N.L. Navarro, G.A. Neves, Rev. Eletr. Mater. Proc. 5, 3 (2010) 65.

[30] J.L. Alves, A.E. Zanini, M.E. de Souza, M.L.F. Nascimento, Cerâmica 62,361 (2016) 1.

[31] J.A. Costa, A.S. Mexias, M.E.B. Gomes, Cerâmica 56, 340 (2010) 360.

[32] P. Cosenza, J.C. Robinet, D. Prêt, E. Huret, M. Fleury, Y. Géraudd, P. Lebon, F. Villiéras, M. Zamora, Mar. Petrol. Geol. 53 (2014) 117.

[33] M.E. Brown, P.K. Gallagher (Eds.), Handbook of thermal analysis and calorimetry, Elsevier (2003).

[34] W.P. Gonçalves, V.J. Silva, J. Gomes, R.R. Menezes, G.A. Neves, H.C. Ferreira, L.N.L. Santana, Cerâmica 60, 355 (2014) 316.

[35] M.E. Alves, Y.P. Mascarenhas, C.M.P. Vaz, Rev. Bras. Ciên. Solo 32 (2008) 569.

[36] I.P. Brito, E.P. Almeida, G.A. Neves, R.R. Menezes, V.J. Silva, L.N.L. Santana, Cerâmica 61, 360 (2015) 391.

[37] C.M.F. Vieira, S.N. Monteiro, Cerâmica 49, 309 (2003) 6.

[38] F.Q. Mariani, J.C. Villalba, F.J. Anaissi, Orbital: Electron. J. Chem. 5, 4 (2013) 249.

[39] S.R. Christofoletti, M.R. Masson, W. Mijolaro, M.M.T Moreno, J.V. Valarelli, Cerâm. Ind. 8 (2003) 35.

[40] M.O. Schwartz, J.A.T.R. Tomé, A.H. Shinohara, L.R.A. Pontes, B.B. Lira, J.I. de Oliveira, in Proc. $48^{\text {th }}$ Ann. Meet. Braz. Ceram. Soc., Curitiba (2004).

[41] R.M. Pinheiro, C.M.F. Vieira, R.S. Rodriguez, S.N.I. Monteiro, Rev. Matér. 13, 1 (2008) 220.

[42] C.C.I. Souza, C.M.F. Vieira, S.N. Monteiro, Rev. Matér. 13, 1 (2008) 194.

[43] C.M.F. Vieira, E.T.A. Souza, S.N. Monteiro, Cerâmica 50, 315 (2004) 254. 
[44] R.C. dos Santos, T.R. da Silva, G.A. Neves, R.S. de Macedo, R.R. Menezes, L.N.L. Santana, Cerâmica 63, 367
(2017) 361 .

(Rec. 21/11/2018, Rev. 15/03/2019, 02/05/2019, Ac. $30 / 05 / 2019)$ 